\author{
Military Technical College \\ Kobry El-Kobbah, \\ Cairo, Egypt.
}

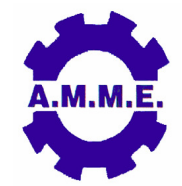

\title{
DYNAMIC BEHAVIOR OF AN ANTISKID BRAKING SYSTEM
}

\author{
A. H. Draz , M. G. Rabie ${ }^{* *}$, A. I. Abdel-Aziz ${ }^{* *}$ and M. S. Dwidar ${ }^{* \star *}$
}

\begin{abstract}
This paper is dedicated to investigate the static and dynamic behavior of a hydro mechanical anti-skid braking system. The system consists of a pilot operated pressure reducing valve and a hydro mechanical anti-skid control unit. The system is designed to fulfill the essential requirements of the anti-skid braking system. The steady state and transient performance of the system and its basic components were investigated considering different operating conditions. Detailed nonlinear mathematical models for the system and its components were deduced considering the tire-ground interface. These mathematical models were used to develop Simulink computer simulation programs. The simulation programs were used to investigate the effect of the constructional and operational parameters on the dynamic behavior of the pilot operated pressure reducing valve; mainly the variation of inlet pressure, spring stiffness, damper radial clearance. The operating characteristics of the braking system with the hydro mechanical anti-skid control unit was investigated and analyzed for the cases of driving over dry and wet concrete pavement. The results are presented and discussed.
\end{abstract}

\section{KEY WORDS}

Antiskid, Antilock, Braking system, Pressure reducer, Fluid power systems, Servo actuator, Relief valve, Dynamic behavior, Dynamics of pneumatic tire.

\footnotetext{
* Egyptian Armed Forces.

** Professor of Mech. Engineering, Modern Academy for Engineering and Technology.

*** Dr., Faculty of Engineering, Ain Shams University.

**** Professor, Faculty of Engineering, Ain Shams University.
} 


\section{NOMENCLATURE}

A Circular area, restriction area and vehicle front area, $\mathrm{m}^{2}$.

$a_{2}$ Length of the valve rocker lever, $m$.

$a_{v}$ Deceleration of the vehicle, $\mathrm{m} / \mathrm{s}^{2}$.

B Bulk modulus of oil, $\mathrm{N} / \mathrm{m}^{2}$.

$b_{1}$ Distance between the return valve and the articulation point of rocker, $m$.

$\mathrm{C}_{\mathrm{s}}$ Longitudinal stiffness of the wheel tire, N/unit skid.

$c_{1}$ Distance between the intake valve and the articulation point of rocker (4), $\mathrm{m}$.

D Diameters, $m$.

d Diameters, $m$.

F Forces, braking forces, reaction forces and springs forces, $\mathrm{N}$.

$f$ Equivalent damping and friction coefficient, N.s/m.

fr Coefficient of the rolling resistance.

H Distances and heights, $m$.

h Heights, $m$.

I Mass moment of inertia, N.m.s2.

is Tire Longitudinal skid.

$\mathrm{K}$ Stiffness of springsand equivalent stiffness, $\mathrm{N} / \mathrm{m}$.

$\mathrm{L}_{\mathrm{A} 1}$ Interference length, $\mathrm{m}$.

$\mathrm{m}$ Reduced masses, Mass of the vehicle, $\mathrm{kg}$.

$\mathrm{n}_{\mathrm{An}}$ Number of opening areas (holes) on the barrel sides.

O Opening distances, $\mathrm{m}$.

$\mathrm{P}$ Pressure, $\mathrm{Pa}$

$Q$ Flow rates, $\mathrm{m}^{3} / \mathrm{s}$.

$\mathrm{R}_{\mathrm{a}}$ Aerodynamic resistance, $\mathrm{N}$. $b_{2} \quad$ Length of the push rod, $m$.

$\mathrm{C}_{\mathrm{A} 1} \quad$ Slide valve (2) clearance, $\mathrm{m}$.

$\mathrm{C}_{\mathrm{A} 2}$ Radial clearance of the damping device, $\mathrm{m}$.

$\mathrm{C}_{\mathrm{ae}}$ Coefficient of the aerodynamic resistance.

$\mathrm{C}_{\mathrm{d}}$ Discharge coefficient.

$r \quad$ Radius, $m$.

$\mathrm{S}_{\mathrm{AB}} \quad$ Stroke, under lap, overlap, opening and closing distances, $\mathrm{m}$.

T Torque, N.m.

t Displacement and initial precompressions, $\mathrm{m}$.

$\mathrm{V}$ Initial volumes, $\mathrm{m}^{3}$.

$v_{v} \quad$ Velocity of the vehicle, $\mathrm{m} / \mathrm{s}$.

$\mathrm{W}_{\mathrm{vw}}$ Share of vehicle normal load on the vehicle wheel tire, $\mathrm{N}$.

$\mathrm{X} \quad$ Displacement and spring initial precompressions, $\mathrm{m}$.

y Displacement and spring initial precompressions, $\mathrm{m}$.

z Displacement and spring initial precompressions, $\mathrm{m}$.

a Angles, rad.

$\mu \quad$ Dynamic viscosity, $\mathrm{kg} / \mathrm{m}$.s, Friction coefficient and of road adhesion coefficient.

$\rho \quad$ Density, $\mathrm{kg} / \mathrm{m} 3$.

$\omega \quad$ Angular speed, $\mathrm{rad} / \mathrm{s}$.

$\omega_{\mathrm{B}} \quad$ Angular deceleration, $\mathrm{rad} / \mathrm{s}^{2}$.

y Instrument error of indicator calibration, \%

\section{NOMENCLATURE OF THE PRESSURE REDUCER MODEL}

A PT $_{\text {Pestriction area, }} \mathrm{m}^{2}$.

$A_{R T}$ Restriction area, $\mathrm{m}^{2}$.

$A_{S P}$ Restriction area, $\mathrm{m}^{2}$.

$\mathrm{A}_{\mathrm{SR}}$ Restriction area, $\mathrm{m}^{2}$.

$\mathrm{C}_{\mathrm{A} 1}$ Slide valve clearance, $\mathrm{m}$.

$\mathrm{C}_{\mathrm{A} 2}$ Radial clearance of damping device, $\mathrm{m}$.

$\mathrm{C}_{d} \quad$ Discharge coefficient.

$D_{A 1}$ Pilot operated control slide valve diameter, $\mathrm{m}$.

$\mathrm{d}_{\mathrm{A} 1}$ Control slide valve rod lower diameter, $\mathrm{m}$.

$d_{A 2}$ Control pressure chamber inner diameter, $\mathrm{m}$.

$\mathrm{D}_{\mathrm{A} 2}$ Piston lower diameter, $\mathrm{m}$.

$d_{A 3}$ Barrel hole diameter, $m$.

$D_{A 3}$ Control pressure chamber outer diameter, $\mathrm{m}$.

$D_{A 4}$ Sleeve inner diameter, $m$.

$d_{A 4}$ Barrel outer diameter, $m$.

$D_{A 5}$ Basic pressure reducer slide valve inner diameter, $\mathrm{m}$.

$d_{A 5}$ Damping spring holder diameter, $m$.

$D_{A 6} \quad$ Damping device outer diameter, $m$.

$d_{A 6}$ Damping device inner diameter, $m$.

$\mathrm{D}_{\mathrm{AP}}$ Intake cone diameter created 
intersection of throttling area and intake cone side, $\mathrm{m}$.

$F_{A E S}$ Relief valve reaction force applied on the basic pressure reducer slide valve, $\mathrm{N}$.

$f_{A E S}$ Equivalent damping of the relief valve material, N.s/m.

$\mathrm{F}_{\mathrm{AS} 1}$ Piston seat reaction force, $\mathrm{N}$.

$\mathrm{f}_{\mathrm{AS} 1}$ Piston seat equivalent material damping, $\mathrm{N} . \mathrm{s} / \mathrm{m}$.

$F_{\text {AS2 }}$ Sleeve seat reaction force, $N$.

$F_{\text {ASE }}$ Basic pressure reducer slide valve reaction force applied on the relief valve, N.

$f_{A t} \quad$ Friction coefficient of the basic pressure reducer slide valve moving parts, N.s/m.

$f_{A y} \quad$ Friction coefficient of the piston moving parts, N.s/m.

$f_{A z}$ Friction coefficient of the relief valve moving parts, N.s/m.

$h_{A 1} \quad$ Control pressure chamber height, $m$.

$h_{A 2}$ Basic pressure reducer slide valve edge height, $\mathrm{m}$.

$\mathrm{H}_{\mathrm{A} 2} \quad$ Damping spring holder height, $\mathrm{m}$.

$\mathrm{h}_{\mathrm{A3}}$ Damping device inner height, $\mathrm{m}$.

$\mathrm{H}_{\mathrm{A} 3}$ interference distance between the rest of Damping device and basic pressure reducer slide valve, $\mathrm{m}$.

$\mathrm{K}_{\mathrm{A} 1} \quad$ Spring (15) stiffness, $\mathrm{N} / \mathrm{m}$.

$\mathrm{K}_{\mathrm{A} 2}$ Spring (14) stiffness, $\mathrm{N} / \mathrm{m}$.

$\mathrm{K}_{\mathrm{A} 3}$ Spring (13) stiffness, $\mathrm{N} / \mathrm{m}$.

$\mathrm{K}_{\mathrm{AES}}$ Equivalent stiffness of the relief valve material, $\mathrm{N} / \mathrm{m}$.

$\mathrm{K}_{\mathrm{AS} 1}$ Piston seat equivalent material stiffness, $\mathrm{N} / \mathrm{m}$.

$\mathrm{K}_{\mathrm{AS2}}$ Equivalent stiffness of the sleeve material, $\mathrm{N} / \mathrm{m}$.

$\mathrm{K}_{\mathrm{ASE}}$ Equivalent stiffness of the basic pressure reducer slide valve material, $\mathrm{N} / \mathrm{m}$.
$\mathrm{m}_{\mathrm{At}}$ Reduced masses of the basic pressure reducer slide valve moving parts, $\mathrm{kg}$.

$\mathrm{m}_{\mathrm{Ay}}$ Reduced masses of the piston moving parts, kg.

$\mathrm{m}_{\mathrm{Az}}$ Reduced masses of the relief valve moving parts, $\mathrm{kg}$.

$P_{D}$ Pressure in Damping device chamber, $\mathrm{Pa}$.

$\mathrm{P}_{\mathrm{P}} \quad$ Pilot control pressure, $\mathrm{Pa}$.

$\mathrm{P}_{\mathrm{R}} \quad$ Reduced (Brake) pressure, $\mathrm{Pa}$.

$P_{S} \quad$ System inlet pressure, $\mathrm{Pa}$.

$\mathrm{P}_{\mathrm{T}} \quad$ Return tank pressure, $\mathrm{Pa}$.

$Q \quad$ Flow rate, $\mathrm{m}^{3} / \mathrm{s}$.

$S_{A B}$ The reduced valve barrel (tappet) stroke, $\mathrm{m}$.

$t_{A}$ basic pressure reducer slide valve displacement, $\mathrm{m}$.

$t_{A 3} \quad$ Spring (13) initial pre-compression, $m$.

$t_{A S 2}$ Sleeve seat initial elastic predeformation, $\mathrm{m}$.

$\mathrm{V}_{\mathrm{BPo}}$ Initial volume of the reduced (Brake) pluming, $\mathrm{m}^{3}$.

$V_{D o}$ Initial volume of the damping device chamber, $\mathrm{m}^{3}$.

$V_{P o}$ Initial volume of the Control pressure chamber, $\mathrm{m}^{3}$.

$\mathrm{x}_{\mathrm{A}}$ pilot operated control slide valve displacement, $\mathrm{m}$.

$\mathrm{y}_{\mathrm{A}} \quad$ piston displacement, $\mathrm{m}$.

$\mathrm{y}_{\mathrm{A} 1} \quad$ Spring (15) initial pre-compression, $\mathrm{m}$.

$\mathrm{y}_{\mathrm{AS} 1}$ Piston seat material initial elastic precompression, $\mathrm{m}$.

$\mathrm{Z}_{\mathrm{A}} \quad$ relief valve displacement, $\mathrm{m}$.

$\mathrm{z}_{\mathrm{A} 2} \quad$ Spring (14) initial pre-compression, $\mathrm{m}$.

$\rho$ Oil density, $\mathrm{kg} / \mathrm{m}^{3}$.

$\mu \quad$ Oil dynamic viscosity, Pa.s.

B Bulk modulus of oil, $\mathrm{N} / \mathrm{m}^{2}$ 


\section{INTRODUCTION}

The hydraulic braking system is a compact method of transmitting the driver's foot-pedal effort to the individual road-wheel brakes by conveying pressurized fluid from one position to another and then converting the fluid pressure into useful work at the wheels to apply the brakes and so retard or stop the rotation of the wheels, Heisler [1].

When a tire is locked, the tire is at $100 \%$ skid. The coefficient of road adhesion falls to its sliding value and its ability to sustain side force is reduced to almost null. As a result, the vehicle will lose directional control and/or stability, and the stopping distance will be longer than

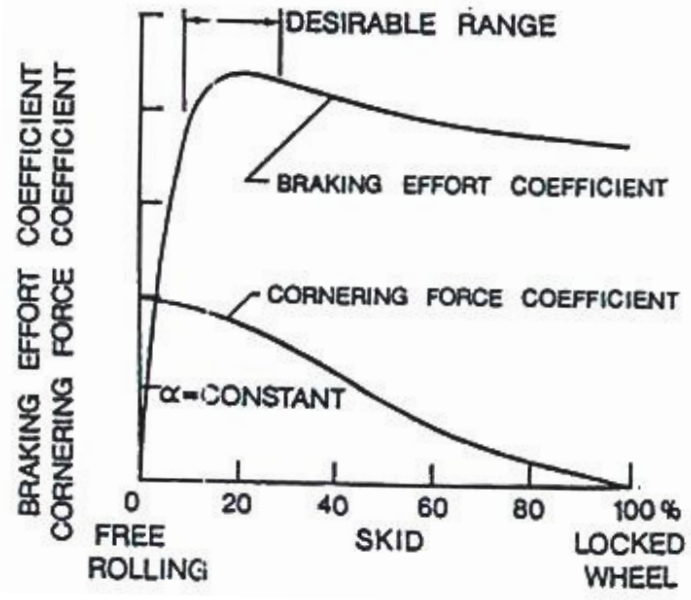

Fig. 1 Effect of skid on cornering force coefficient of a tire [2]. the minimum achievable.

Figure 1 shows the general characteristics of the braking effort coefficient (i.e. the ratio of the braking effort to the normal load of the tire) and the coefficient of cornering force (i.e. the ratio of the cornering force to the normal load of the tire) at a given slip angle as a function of skid for a pneumatic tire. This paper is dedicated to investigate the dynamic performance of a hydraulic braking system equipped with an antiskid arrangement.

\section{DESCRIPTION OF THE STUDIED SYSTEM}

The studied system, Fig. 2, is a hydro- mechanical anti-skid wheel braking system. The system consists of a closed hydraulic circuit ensuring operating fluid supply to the wheel brakes and a mechanical linkage (pedals) controls the hydraulic pilot operated pressure reducing valve (1) through the braking system mechanisms. The operating fluid under the system pressure is delivered to the pilot operated pressure reducing valve (1). As the braking control pedal is pressed, the motion is transmitted to the pilot operated pressure reducing valve (1) providing a pressure proportional to the pedal displacement. The pilot operated pressure reducing valve is adjusted so that with the pedals pressed to the stop, a pressure of within 100 bar is built in the brakes. The operating fluid then flows through the hydro mechanical anti-skid control unit (2) and is supplied to the braking actuator cylinder (3) with a resultant braking of the wheels. During operation of the hydro mechanical anti-skid control unit (2), the operating fluid is allowed to flow out of the brakes directly into the return line. The main hydraulic power source of the system is a pressure compensated variable delivery hydraulic pump. It works at a constant pressure of 150 bar; the maximum delivery rate is $27 \mathrm{l} / \mathrm{min}$. The system has a $2500 \mathrm{~cm}^{3}$ accumulator capacity. The variable delivery pump with its constant delivery pressure and high flow rate beside the presence of the large capacity accumulator in the circuit, and according to experience in such large systems, leads to consider the system is fed with a constant pressure of 150 bar with insignificant variation. Scope of study is focused 


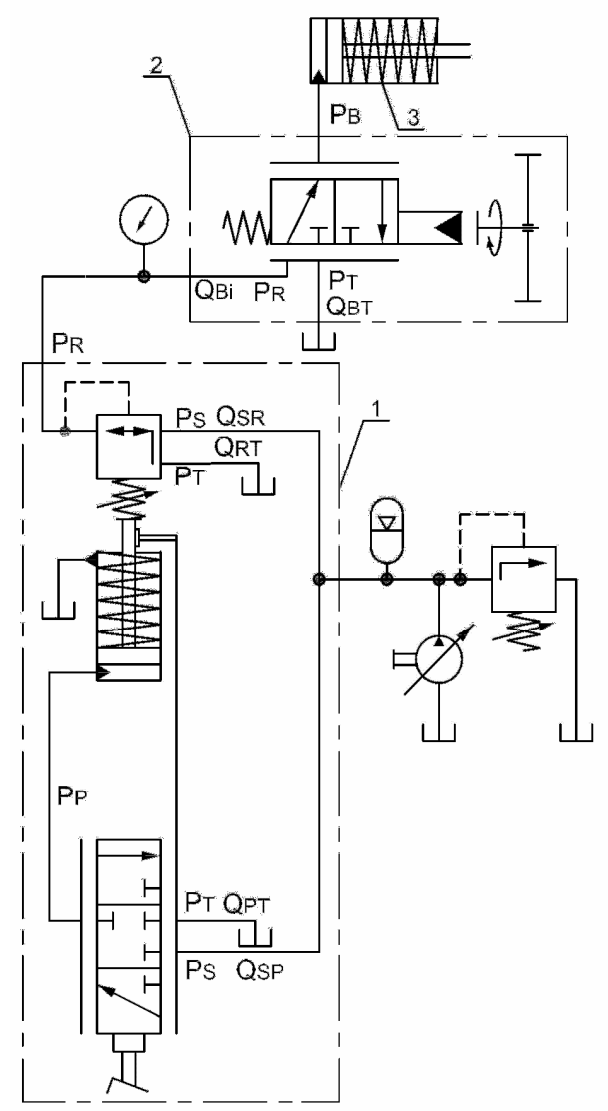

1. Pressure reducing valve piloted by a hydraulic servo actuator, 2. Antiskid unit, 3. Brakes actuator

Fig. 2 The anti-skid braking system.

on the pilot operated (servo actuator) pressure reducing valve (1) and the hydro mechanical anti-skid control unit (2) as they can be considered the main effective components at the static and dynamic performance of the system.

\section{ANALYSIS OF THE PRESSURE REDUCING VALVE}

The static and dynamic performance of the built-in hydraulic pressure reducer was studied and published by Draz et al [3]. The modeling and simulation of the of the pressure reducer are summarized in the following.

\section{Mathematical Model}

A schematic of the hydraulic pressure reducer with built-in hydraulic servo-actuator and relief valve is shown in Fig.3. The following equations were deduced systematically to describe the valve dynamic behavior.

Continuity equation applied to the pilot chamber (A)

$Q_{S P}-Q_{P T}-\left(A_{A D 3}-A_{A D 1}\right) \frac{d y_{A}}{d t}=\left(\frac{V_{P o}+\left(A_{A D 3}-A_{A D 1}\right) y_{A}}{B}\right) \frac{d}{d t}\left(P_{P}\right)$ 


$$
\begin{aligned}
& \mathrm{A}_{\mathrm{AD} 3}=\frac{\pi}{4} \mathrm{D}_{\mathrm{A} 3}^{2} \\
& \mathrm{~A}_{\mathrm{AD} 1}=\frac{\pi}{4} \mathrm{D}_{\mathrm{A} 1}^{2} \\
& \mathrm{~V}_{\mathrm{Po}}=\frac{\pi}{4}\left(\mathrm{~d}_{\mathrm{A} 2}^{2}-\mathrm{d}_{\mathrm{A} 1}^{2}\right) \mathrm{h}_{\mathrm{A} 1}
\end{aligned}
$$

Flow rates through the restriction areas of the slide valve (2) and the piston (3).

$Q_{\mathrm{SP}}=C_{d} A_{S P} \sqrt{\frac{2\left(P_{S}-P_{P}\right)}{\rho}}$
$Q_{P T}=C_{d} A_{P T} \sqrt{\frac{2\left(P_{P}-P_{T}\right)}{\rho}}$

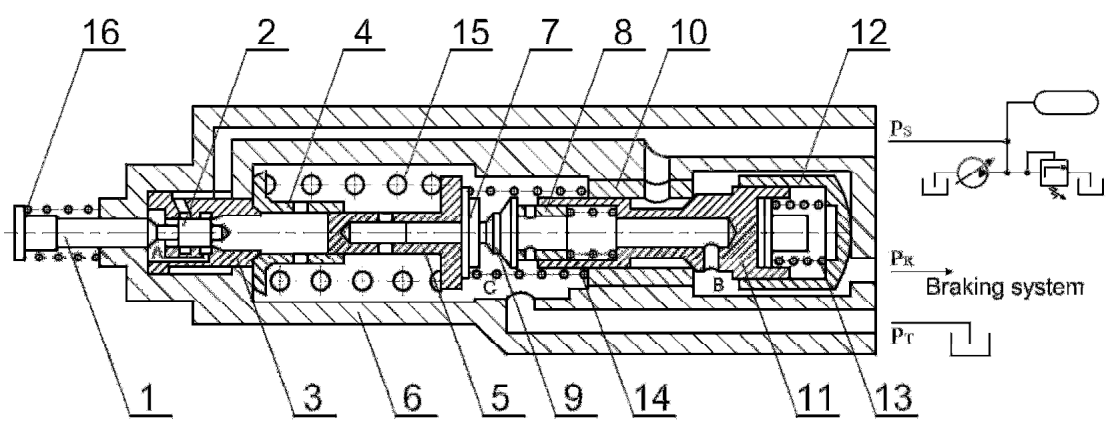

1-Braking rod, 2- Control slide valve, 3. Piston, 4- Guide, 5- Support, 6- Casigng, 7- Holder, 8- Barrel, 8- Relief valve, 9- Sleeve, 10- Pressure reducing, valve, 11- Damper, 12- Spring, 13, 14\& 15- Spring.

Fig. 3 Schematic diagram of the pilot operated pressure reducing valve.

Equation of motion of the piston (3)

$$
\begin{aligned}
& F_{A S 1}+\frac{\pi}{4}\left(D_{A 3}^{2}-D_{A 1}^{2}\right) P_{P}-\frac{\pi}{4}\left(D_{A 3}^{2}-D_{A 2}^{2}\right) P_{S}-\frac{\pi}{4}\left(D_{A 2}^{2}-D_{A 1}^{2}\right) P_{T}= \\
& m_{A y}\left(\ddot{y}_{A}\right)+f_{A y}\left(\dot{y}_{A}-\dot{z}_{A}\right)+K_{A 1}\left(y_{A}-z_{A}+y_{A 1}\right) \\
& F_{A S 1}=\left\{\begin{array}{lc}
-K_{A S 1}\left(y_{A}-y_{A S 1}\right)-f_{A S 1} \dot{y}_{A} & \text { for } y_{A}<y_{A S 1} \\
\text { Zero } & \text { for } y_{A} \geq y_{A S 1}
\end{array}\right.
\end{aligned}
$$

Mathematical Model of Relief valve (9) and Pressure Reducing Slide Valve (11) Continuity equation applied to reduced pressure chamber (B)

$$
Q_{S R}+Q_{D}-Q_{R T}=\left(\frac{V_{B P o}}{B}\right) \frac{d}{d t}\left(P_{R}\right)
$$

Continuity equation applied to the damping pressure chamber (D) 


$$
\begin{aligned}
& \frac{\pi}{4} D_{A 6}^{2} \frac{d t_{A}}{d t}-Q_{D}=\left(\frac{V_{D 0}-\left(\frac{\pi}{4} D_{A 6}^{2}\right) t_{A}}{B}\right) \frac{d}{d t}\left(P_{D}\right) \\
& V_{D 0}=\frac{\pi}{4}\left(d_{A 6}^{2} h_{A 3}+D_{A 6}^{2} H_{A 3}+D_{A 5}^{2} h_{A 2}-d_{A 5}^{2} H_{A 2}\right)
\end{aligned}
$$

Flow rates through the pressure reducing slide valve (11) and the relief valve (9)

$$
\begin{aligned}
& Q_{S R}=C_{d} A_{S R} \sqrt{\frac{2\left(P_{S}-P_{R}\right)}{\rho}} \\
& Q_{R T}=C_{d} A_{R T} \sqrt{\frac{2\left(P_{R}-P_{T}\right)}{\rho}} \\
& Q_{D}=\frac{\pi D_{A 6} C_{A 2}^{3}}{12 \mu\left(L_{A 1}+t_{A}\right)}\left(P_{D}-P_{R}\right)
\end{aligned}
$$

Equation of motion of the relief valve (9)

$$
\begin{aligned}
& \frac{\pi}{4} d_{A 4}^{2}\left(P_{T}-P_{R}\right)-F_{A S E}=m_{A Z} z_{A}+f_{A Z}\left(\dot{z}_{A}-\dot{y}_{A}\right)+K_{A 2}\left(z_{A}+z_{A Z}\right)+K_{A 1}\left(z_{A}-y_{A}-y_{A 1}\right) \\
& F_{A S E}=\left\{\begin{array}{lc}
K_{A S E}\left(z_{A}-S_{A B}-t_{A}\right)+f_{A S E}\left(\dot{z}_{A}-\dot{t}_{A}\right) & \text { for }\left(z_{A}-t_{A}\right)>S_{A B} \\
\text { Zero } & \text { for }\left(z_{A}-t_{A}\right) \leq S_{A B}
\end{array}\right.
\end{aligned}
$$

Equation of motion of the basic pressure reducing slide valve (11)

$$
\begin{aligned}
& m_{A t} t_{A}+f_{A t} \dot{t}_{A}+K_{A 3}\left(t_{A}+t_{A 3}\right)=\frac{\pi}{4}\left(d_{A 4}^{2}+D_{A 6}^{2}-D_{A P}^{2}\right) P_{R}+\frac{\pi}{4}\left(D_{A 4}^{2}-d_{A 4}^{2}\right) P_{T}-\frac{\pi}{4}\left(D_{A 4}^{2}-D_{A P}^{2}\right) P_{S} \\
& -\frac{\pi}{4} D_{A 6}^{2} P_{D}+F_{A E S}+F_{A S 2} \\
& F_{A E S}=\left\{\begin{array}{lc}
K_{A E S}\left(z_{A}-S_{A B}-t_{A}\right)+f_{A E S}\left(\dot{z}_{A}-\dot{t}_{A}\right) & \text { for }\left(z_{A}-t_{A}\right)>S_{A B} \\
\text { Zero } & \text { for }\left(z_{A}-t_{A}\right) \leq S_{A B}
\end{array}\right. \\
& F_{A S 2}= \begin{cases}-K_{A S 2}\left(t_{A}-t_{A S 2}\right)-f_{A S 2} t_{A} & \text { for } t_{A}<t_{A S 2} \\
\text { Zero } & \text { for } t_{A} \geq t_{A S 2}\end{cases}
\end{aligned}
$$




\section{Simulation of the Pressure Reducer}

The dynamic behavior of the pressure reducing slide valve incorporating a hydraulic servo-actuator and relief valve is described by Eqs. 1 thru 20. These equations were applied to develop a computer simulation program using the SIMULINK software package. The transient response of the pressure reducing slide valve to a step input displacement is calculated using the simulation program. A sample of calculations results are plotted in Fig.4. This figure shows the effect of radial clearance of the damping element on the transient response of the valve. The study was extended to investigate the effect of different constructional and operational parameters on the system performance

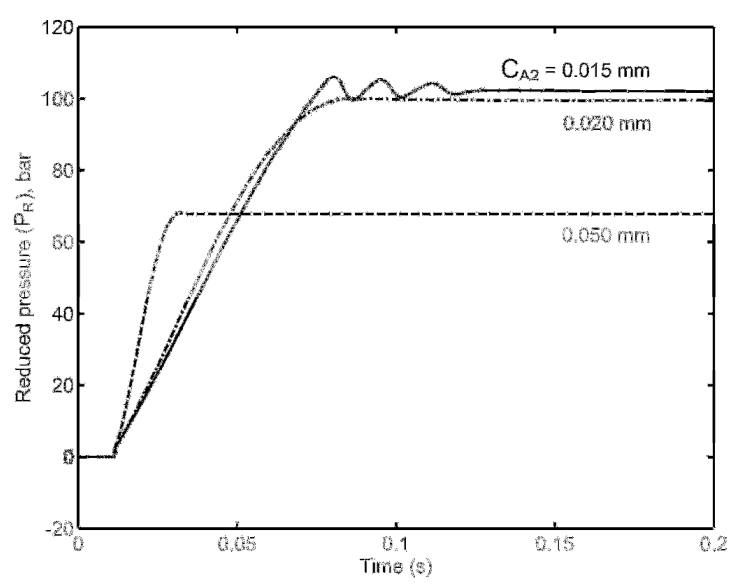

Fig. 4 The dynamic response of the reduced pressure $(P R)$ with different radial clearances $\mathrm{CA} 2=0.015,0.020$ and $0.050 \mathrm{~mm}$ of the damping device [12].

\section{ANALYSIS OF THE HYDRO-MECHANICAL ANTI-SKID UNIT}

\section{Description and Operation of the Hydro Mechanical Anti-Skid Control Unit}

The hydro mechanical anti-skid control unit, Fig. 5, is designed for a vehicle braking system to prevent skidding of the wheels during braking. This unit releases wheel brakes when the rate of rotational deceleration of the skid detector shaft exceeds a threshold value. It consists of a lever mechanism, Fig. 5.a, an inertia mechanism and a distributor, Figs. 5.b and 6. During adjustment of the distributor, a clearance is provided between the intake needle valve (5) and its seat (18) to provide flow of the working fluid to the high-pressure space (22). The initial position of the intake (5) and return (6) valves, Fig. 7.a, provides delivery of the working fluid from the pressure reducing valve to the brake assembly as well as working fluid return from the brake assembly to the pressure reducing valve (wheel braking and brake release action by the pressure reducing valve). During braking, the wheel starts to decelerate together with the drive shaft (16), hence the flywheel (9) becomes a driving element. The flywheel transmits a moment proportional to the rate of deceleration of the drive shaft of the hydro mechanical anti-skid control unit to the friction clutch body (10). Under the action of the applied moment, the friction clutch body (10) overruns the drive shaft (16) of the mechanical anti-skid control unit.

This makes the push rod (14), which rests against the countersunk faces of the friction clutch body (10), moves along the drive shaft (16) axis towards the pivot of the push rod lever (8). At a certain angular deceleration of the drive shaft (16) which corresponds to the preset response value of the mechanical anti-skid control unit, the push rod (14) overcomes the force of spring (20) and pivots the push rod lever (8). The push rod lever pivots the rocker (4) with the needles intake valve (5) and return valve (6) through the pivot pin (2). As a result, the intake valve (5) cuts off the 
pressure line; the return valve (6) communicates the brakes line to the return line and thence the wheel brakes are released, Fig. 7.b. The drive shaft (16) accelerates, the flywheel (9) ceases to be the driving element of the friction clutch body and the spring (20) returns the push rod (14) to the initial position. Concurrently, the needle valves also return to the initial position, provide working fluid supply to the brakes and pressure build-up in the braking system. The wheel braking acting and releasing processes continue achieving maximum braking efficiency without wheels lock.

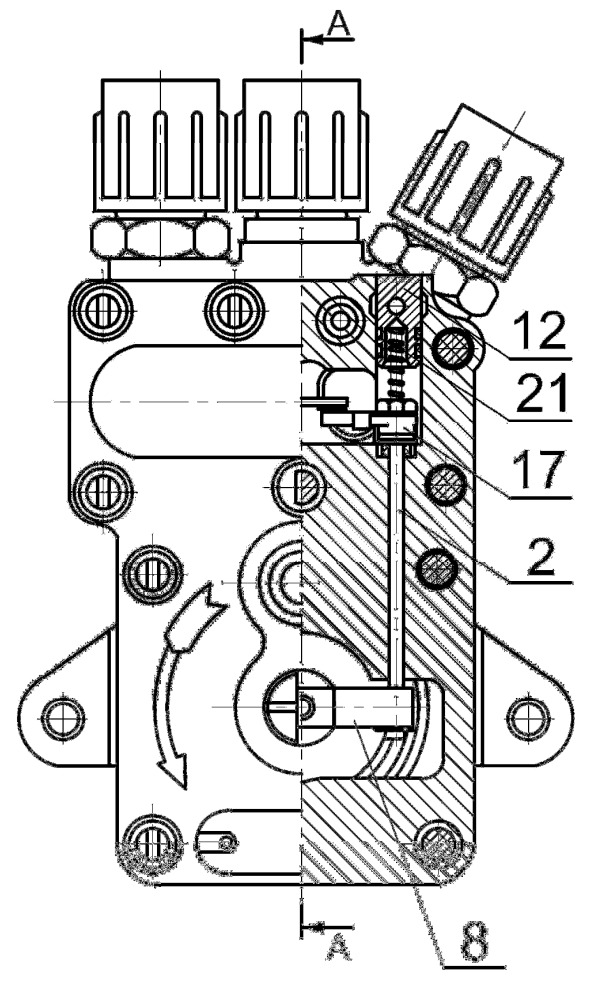

a.Schematic of the lever mechanism.

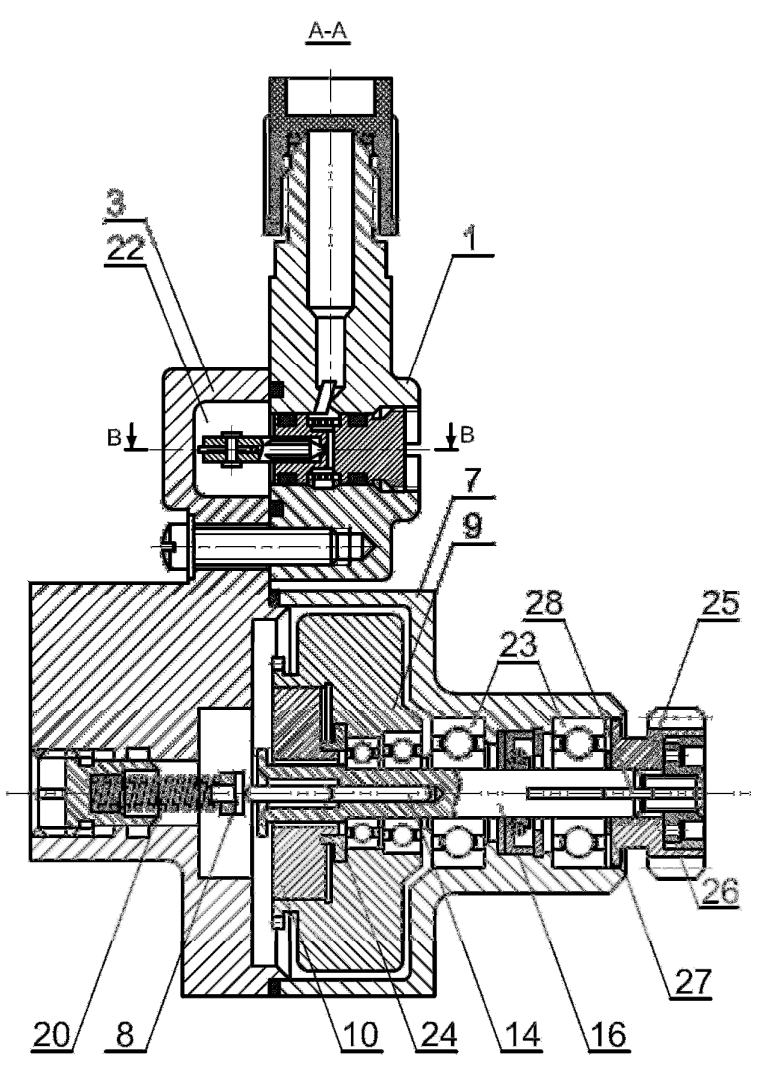

b. Section A-A, the distributor and the inertia mechanism schematic drawing.

1. Distributor body, 2. Pivot pin, 3.Lever mechanism body, 7. Body, 8. Push rod, 9. Flywheel, 10. Friction clutch body, 12. Plug, 14. Push rod, 16. Drive shaft, 17. Rocker lever, 20. Spring, 21. Spring, 22. High-pressure space, 23. Ball bearing, 24. Sleeve, 25. Gear, 26. Nut, 27. Shim, 28. Key.

Fig. 5 Lever-type mechanism, section A-A, the distributor and the inertia-type mechanism schematic drawing.

\section{Mathematical Model of the Mechanical Anti-Skid Control Unit}

\section{Mathematical model of the distributor}

Figure 8 shows a schematic of the distributor. The following are the equations describing this valve. The flow rate through the intake valve (5) is determined by

$$
Q_{B i}=C_{d} A_{B i} \sqrt{\frac{2\left(P_{R}-P_{B}\right)}{\rho}}
$$




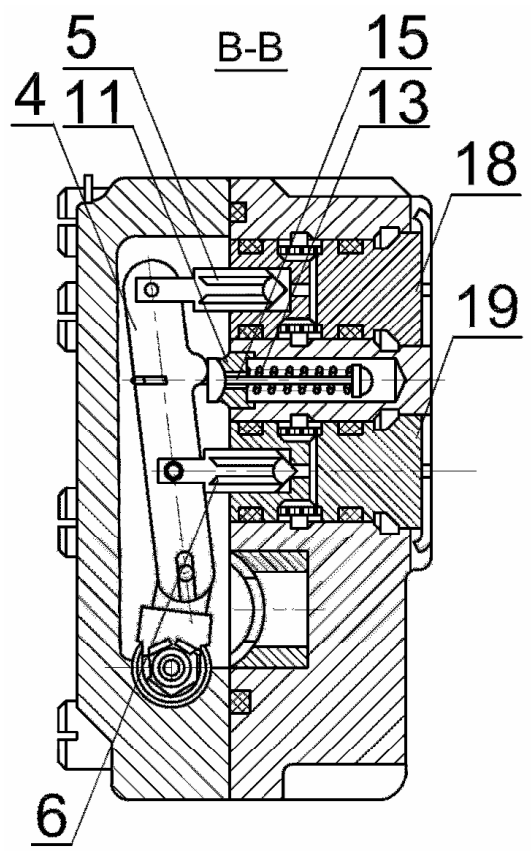

4. Rocker, 5. Intake valve, 6. Return valve, 11. Rocker stop, 13. Spring, 15. Link, 18. Intake valve seat, 19. Return valve seat.

Fig. 6 Section B-B, the distributor and the lever mechanism.

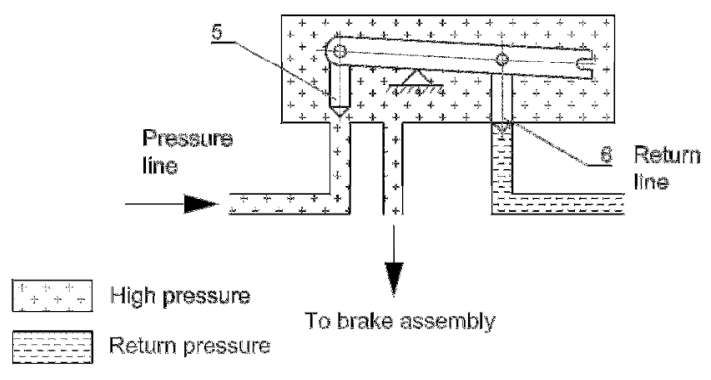

a. Wheel brake application.

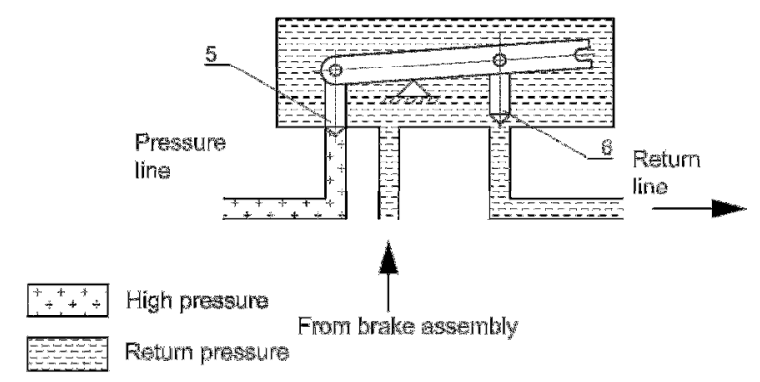

b. Wheel brake release

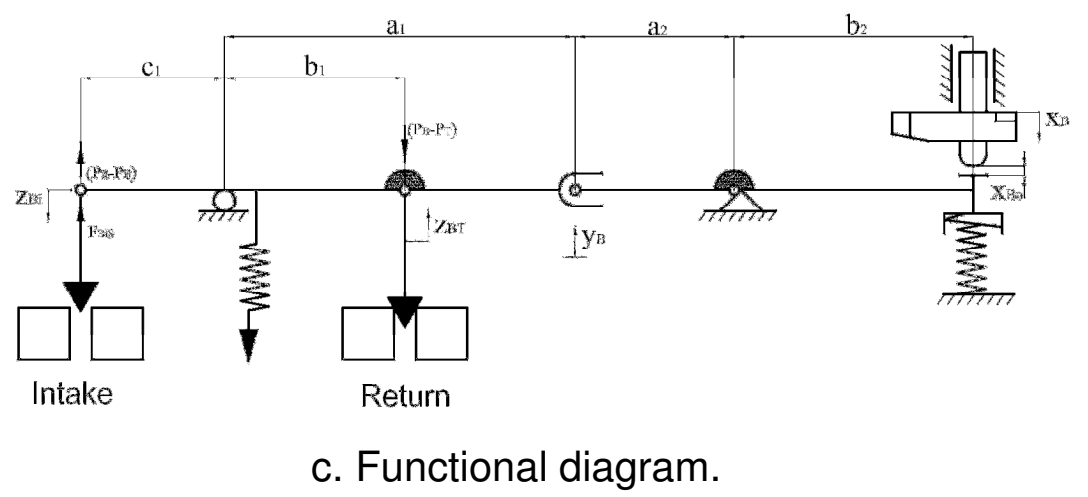

Fig. 7 Functional diagram of the hydro mechanical anti-skid control unit. 
The flow rate through the return valve (6) is determined by

$Q_{B T}=C_{d} A_{B T} \sqrt{\frac{2\left(P_{B}-P_{T}\right)}{\rho}}$

The restriction area $\left(A_{B i}\right)$ connects the reduced pressure and the braking pressure chambers. This area changes nonlinearly with the displacement $\left(\mathrm{z}_{\mathrm{Bi}}\right)$ of the distributor intake valve (5). Figure 9 shows the conical poppet valve in closed and open positions. A mathematical expression for this valve area is deduced in the following.

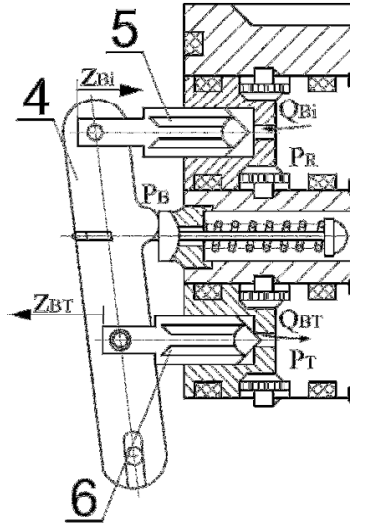

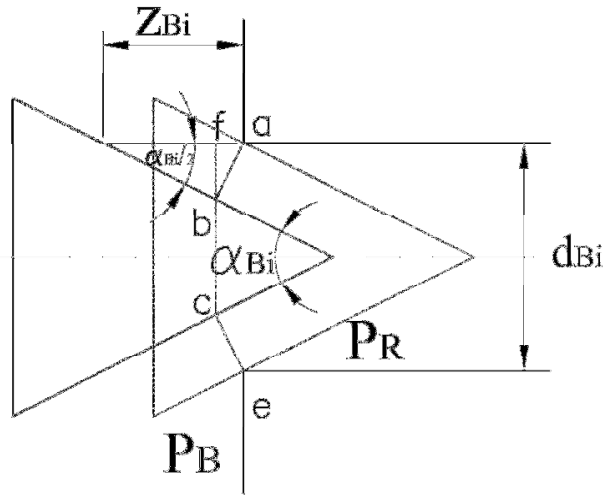

Fig. 9 Geometric drawing of a poppet cone.

Fig. 8 Flow rates through the distributor.

$$
\begin{aligned}
& A_{B i}= \begin{cases}\pi O_{B i} \sin \left(\frac{\alpha_{B i}}{2}\right)\left[d_{B i}-O_{B i} \sin \left(\frac{\alpha_{B i}}{2}\right) \cos \left(\frac{\alpha_{B i}}{2}\right)\right] & \text { for } z_{B i} \leq z_{B i o}<Z_{B i X} \\
Z \text { ero } & \text { for } Z_{B i} \geq z_{B i o}\end{cases} \\
& O_{B i}=z_{B i o}-z_{B i} \\
& z_{B i X}=d_{B i} / 2 \tan \left(\frac{\alpha_{B i}}{2}\right)
\end{aligned}
$$

The poppet cone area $\left(A_{B i P}\right)$ of the intake valve (5) subjected to the reduced pressure $\left(P_{R}\right)$ also changes nonlinearly with the displacement $\left(\mathrm{Z}_{\mathrm{Bi}}\right)$ of the distributor intake valve (5).

$$
\begin{aligned}
& \overline{\mathrm{bc}}=\mathrm{d}_{\mathrm{BiP}} \\
& A_{B i P}=\frac{\pi}{4} d_{B i P}^{2} \\
& d_{B i P}= \begin{cases}d_{B i} & \text { for } z_{B i} \geq z_{B i o} \\
d_{B i}-2\left[\left(z_{B i o}-z_{B i}\right) \sin \left(\frac{\alpha_{B i}}{2}\right) \cos \left(\frac{\alpha_{B i}}{2}\right)\right] & \text { for zero } \leq z_{B i}<z_{B i o}\end{cases}
\end{aligned}
$$


In addition, the restriction area $\left(\mathrm{A}_{B T}\right)$ through the return pressure $\left(\mathrm{P}_{T}\right)$ and the braking pressure $\left(P_{B}\right)$ in the high-pressure space (22), changes nonlinearly with the displacement $\left(\mathrm{z}_{\mathrm{BT}}\right)$ of the distributor return valve, as shown by the following equations.

$A_{B T}= \begin{cases}\pi z_{B T} \sin \left(\frac{\alpha_{B T}}{2}\right)\left[d_{B T}-z_{B T} \sin \left(\frac{\alpha_{B T}}{2}\right) \cos \left(\frac{\alpha_{B T}}{2}\right)\right] & \text { for zero }<Z_{B T}<Z_{B T X} \\ Z \text { Zero } & \text { for } z_{B T}=\text { zero }\end{cases}$

$\mathrm{z}_{\mathrm{BTX}}=\frac{1}{2} \mathrm{~d}_{\mathrm{BT}} \tan \left(\frac{\alpha_{\mathrm{BT}}}{2}\right)$

The poppet cone area ( $\left.A_{B T P}\right)$ of the return valve (6) subjected to the return pressure $\left(P_{T}\right)$ is given by the following relations.

$$
\begin{aligned}
& A_{\mathrm{BTP}}=\frac{\pi}{4} \mathrm{~d}_{\mathrm{BTP}}^{2} \\
& d_{B T P}= \begin{cases}d_{B T} & z_{B T}=\text { zero } \\
d_{B T}-2\left[z_{B T} \sin \left(\frac{\alpha_{B T}}{2}\right) \cos \left(\frac{\alpha_{B T}}{2}\right)\right] & 0<z_{B T}<Z_{B T X}\end{cases}
\end{aligned}
$$

The displacements of the lever mechanism and the rocker are related by the following equations.

$$
\begin{aligned}
& z_{B i}=\frac{c_{1}}{a_{1}} y_{B} \\
& z_{B T}=\frac{b_{1}}{a_{1}} y_{B} \\
& y_{B}=\left(x_{B}-x_{B 0}\right) \frac{a_{2}}{b_{2}}
\end{aligned}
$$

The application of the continuity equation to the high-pressure chamber (22) yields:

$$
Q_{B i}-Q_{B T}=\left(\frac{V_{B B o}}{B}\right) \frac{d}{d t}\left(P_{B}\right)
$$

\section{Mathematical model of the inertia mechanism}

Upon application of the braking action, the breaking torque is transmitted to the push rod (14) through the drive shaft (16) and the gear (25), Fig. 5.In addition, the pressure forces acting on both the intake valve (5) and the return valve (6) are transmitted to the push rod (14) through the lever mechanism. The transmitted braking torque $\left(T_{B b}\right)$ results in an axial force component $\left(F_{R B b} \sin \alpha_{B}\right)$, due to the mesh teeth angle $\left(\alpha_{B}\right)$ of the friction clutch body (10) and the push rod (14). This axial force acts on the friction clutch body (10). Consequently, an equal axial force $\left(F_{B R b} \sin \alpha_{B}\right)$ will react on the push rod (14) and causes it to move toward the push rod lever (8), Fig. 10.

$$
\begin{aligned}
& T_{B b}=r_{B R} F_{R B b} \cos \alpha_{B} \\
& F_{B R b}=F_{R B b}
\end{aligned}
$$


While decelerating of the push rod (14) and the friction clutch body (10), the flywheel (9) will tend to drive the friction clutch body (10) and originates a torque $\left(\mathrm{T}_{\mathrm{BC}}\right)$ due to friction. This torque is also transmitted to the push rod (14). With the mesh teeth angle $\left(\alpha_{B}\right)$, the transmitted torque $\left(T_{B C}\right)$ adds an axial force component, $F_{B R C} \sin \left(\alpha_{B}\right)$, acting on the push rod (14) and cause it to move toward the push rod lever (8).

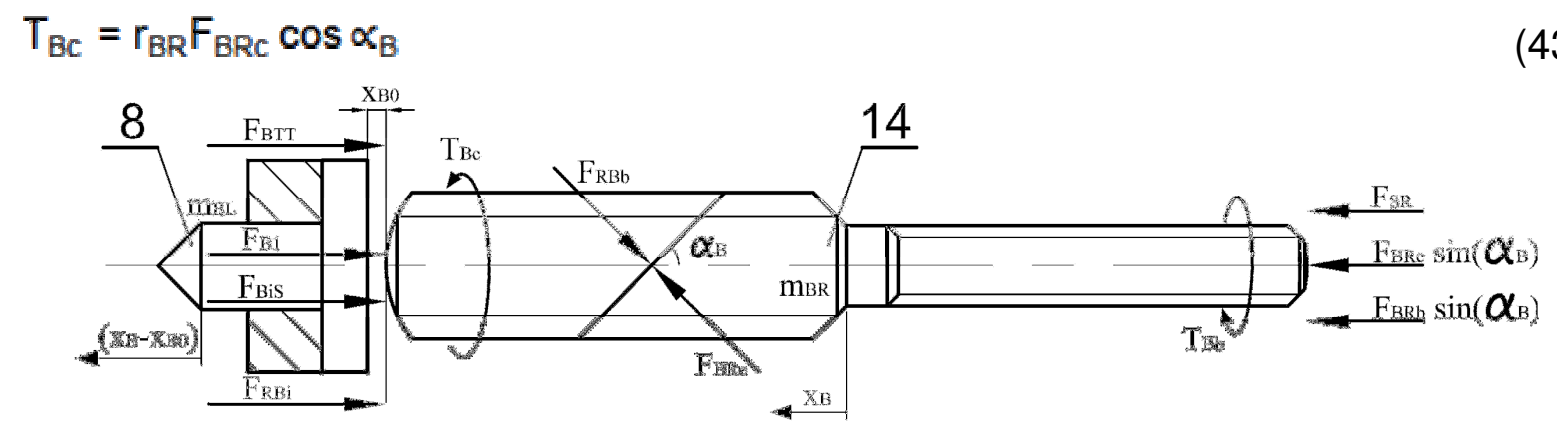

Fig. 10 Free body diagram of the push rod.

The total axial forces due to both transmitted braking torque $\left(\mathrm{T}_{\mathrm{Bb}}\right)$ and the torque $\left(\mathrm{T}_{\mathrm{BC}}\right)$ due to the friction can be described as follows:

$F_{\mathrm{BR}}=\left(F_{\mathrm{BRb}}+F_{\mathrm{BRC}}\right) \sin \propto_{\mathrm{B}}$

The forces and the moments acting on the push rod (14) in the axial direction are shown in Fig. 10 and described in equations 45 thru54.

$$
\begin{aligned}
& m_{B X} \ddot{x}_{B}+f_{B x} \dot{x}_{B}=F_{B R}+F_{S R}-F_{B 1}-F_{B i S}-F_{R B i}-F_{B T T} \\
& I_{B x} \dot{\omega}_{B}+f_{B 1} \omega_{B}=T_{B C}-T_{B b}
\end{aligned}
$$

The motion of the flywheel (9) can be described by the following equation.

$I_{B C} \omega_{B C}+f_{B C} \omega_{B C}=-T_{B C}$

The torque $\left(\mathrm{T}_{\mathrm{BC}}\right)$, due to friction, is transmitted between the flywheel (9) and the friction clutch body (10). It acts in the opposite direction of the angular deceleration of the rotating parts $\left(\omega_{\mathrm{B}}\right)$ and affects both the flywheel $(9)$ and the friction clutch body $(10)$ until the angular speed $\left(\omega_{\mathrm{BC}}\right)$ of the flywheel $(9)$ matches the angular speed $\left(\omega_{\mathrm{B}}\right)$ of the rotating parts. Consequently, the magnitude of the torque $\left(T_{\mathrm{BC}}\right)$ decreases to the value of $\left(-f_{B C} \omega_{B C}\right)$ in order to keep the angular speed $\left(\omega_{B C}\right)$ of the flywheel $(9)$ constant (for $\omega_{B}=\omega_{B C} T_{B C}=-f_{B c} \omega_{B c}$ ). The torque $\left(T_{B c}\right)$ now can be described as follows

$T_{B c}= \begin{cases}r_{B c}\left(\mu_{B c} F_{B c}\right) & \text { for } \omega_{B c}>\omega_{B} \\ -f_{B c} \omega_{B c} & \text { for } \omega_{B c}=\omega_{B} \\ -r_{B c}\left(\mu_{B c} F_{B c}\right) & \text { for } \omega_{B c}<\omega_{B}\end{cases}$

The variation of the reduced mass of the moving parts $\left(m_{B x}\right)$ due to the contact of the push rod (14) and the push rod lever (8) is described by the following equation.

$m_{B x}= \begin{cases}m_{B R}+m_{B L} & \text { for } x_{B} \geq x_{B o} \\ m_{B R} & \text { for } x_{B}<x_{B O}\end{cases}$ 
The reaction force of the drive shaft (16) applied to the push rod (14) exists only when both are in touch, so;

$F_{S R}= \begin{cases}K_{B S S}\left(x_{B}\right)+f_{B S S} \dot{x}_{B} & \text { for } x_{B}<\text { Zero } \\ \text { Zero } & \text { for } x_{B} \geq \text { Zero }\end{cases}$

The force of the spring (20) acting on the push rod (14) appears only when it moves a distance $\left(\mathrm{x}_{\mathrm{B} O}\right)$ and contacts the push rod lever (8), thus

$F_{B 1}= \begin{cases}K_{B 1}\left(x_{B}-X_{B 0}+X_{B 10}\right) & \text { for } x_{B}>X_{B o} \\ \text { Zero } & \text { for } x_{B} \leq x_{B o}\end{cases}$

When the intake valve (5) is completely closed, the intake valve seat (18) reaction force acts on the push rod (14) through the lever-type mechanism and prevents further movement of the push rod (14), thus:

$F_{B i s}= \begin{cases}\left(\frac{C_{1}}{a_{1}} \times \frac{a_{2}}{b_{2}}\right)\left[K_{B i S}\left(Z_{B i}-Z_{B i o}\right)+f_{B i s} z_{B i}\right] & \text { for } z_{B i}>Z_{B i o} \\ Z \text { ero } & \text { for } Z_{B i} \leq Z_{B i o}\end{cases}$

The pressure forces acting on the intake valve (5) and transmitted to the push rod (14) through the lever-type mechanism are described as follow

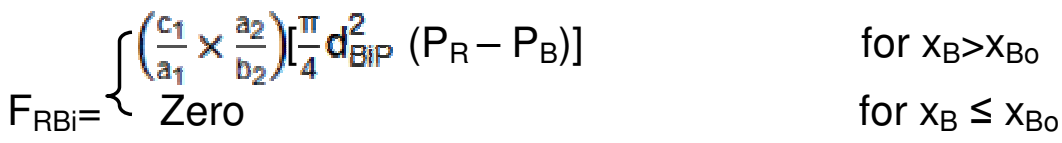

The pressure forces acting on the return valve (6) and transmitted to the push rod (14) through lever-type mechanism are described as follow.

$F_{B T T}= \begin{cases}\left(\frac{b_{1}}{a_{1}} \times \frac{a_{2}}{b_{2}}\right)\left[\frac{\pi}{4} d_{B T P}^{2}\left(P_{B}-P_{T}\right)\right] & \text { for } x_{B}>x_{B O} \\ \text { Zero } & \text { for } x_{B} \leq x_{B O}\end{cases}$

\section{Mathematical mode of the vehicle}

The braking force $\left(\mathrm{F}_{\mathrm{b}}\right)$ created from the braking system and built-up on the tire-road interface is the major decelerating force. When the braking force $\left(F_{b}\right)$ is below the tire-road adhesion, the braking force is given by

$F_{b}=\frac{T_{b}-\sum I_{w} \dot{\omega}_{w}}{r_{w w}}$

Beside the braking force, the rolling resistance of tires, the aerodynamic resistance, the transmission resistance and the grade resistance (when moving on a slope) also influence vehicle motion during braking. The magnitude of transmission resistance is small and can be neglected in braking performance calculations, [2]. Grade resistance can be ignored assuming traveling on a plain road. Thus, the vehicle equation of motion can be expressed by

$F_{\mathrm{b}}+\mathrm{f}_{\mathrm{r}} \mathrm{m}_{\mathrm{v}} \mathrm{g}+\mathrm{R}_{\mathrm{a}}=\mathrm{m}_{\mathrm{y}} \mathrm{a}_{\mathrm{y}}$

$R_{\mathrm{a}}=\mathrm{C}_{\mathrm{D}} A_{\mathrm{f}} \frac{\rho_{\mathrm{a}}}{2} \mathrm{v}_{\mathrm{v}}^{2}=\mathrm{C}_{\mathrm{ae}} \mathrm{v}_{\mathrm{v}}^{2}$ 
When a braking torque is applied to the tire, a stretching of the tread elements occurs prior to entering the contact area. The distance that the tire travels when a braking torque is applied, therefore, will be greater than that in free rolling. The severity of braking is often measured by the amount of longitudinal skid developed by the tire; $i_{s}$.

$i_{s}=\left(1-\frac{r_{w w} w_{w}}{v_{v}}\right) \times 100 \%$

Figure 11 shows the change of braking effort $\left(F_{b w}\right)$ and longitudinal skid of the tire $\left(i_{s}\right)$. This non-linear relationship is used for the calculations of the braking effort developed by the wheel tire.

For a locked wheel, the angular speed $\left(\omega_{\mathrm{w}}\right)$ of the tire is zero, whereas the linear speed of the tire center $\left(v_{v}\right)$ is not zero. Under this condition, the skid is denoted $100 \%$. [2].When no sliding takes place on the contact patch, the relationship between the braking effort $\left(F_{b w}\right)$ and the skid $\left(i_{s}\right)$ is given by

$F_{b w}=\frac{C_{s} i_{s}}{\left(1-i_{s}\right)}$

The braking effort $\left(F_{b w}\right)$ is acting in the opposite direction of motion of the wheel tire center, and $\left(\mathrm{C}_{\mathrm{s}}\right)$ is the slope of the braking effort-skid curve at the origin. The relationship between braking effort $\left(F_{b w}\right)$ and skid $\left(i_{s}\right)$ is nonlinear, even at low skids, where no sliding takes place between the tread and the ground. The critical value of skid $\left(i_{s c}\right)$ at which sliding between the tread and the ground occurs can be given by

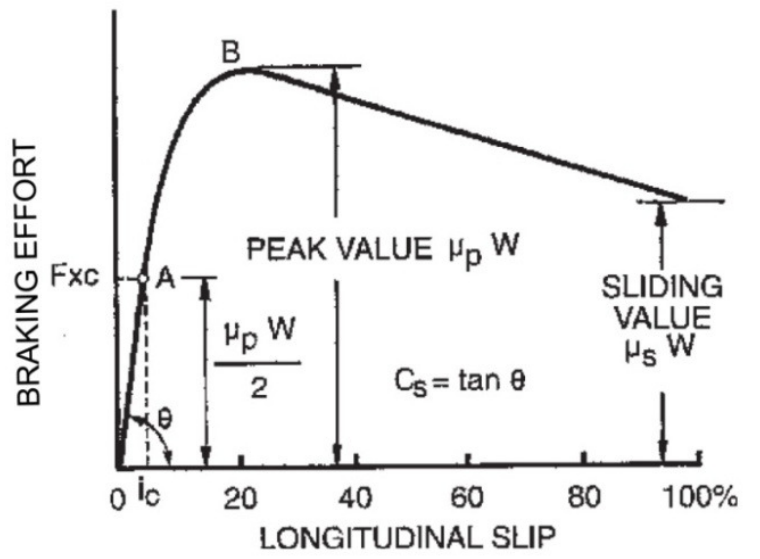

Fig. 11 Variation of braking effort with longitudinal skid of a tire [2].

$\mathrm{i}_{\mathrm{sc}}=\frac{\mu_{\mathrm{p}} \mathrm{W}_{\mathrm{ww}}}{2 \mathrm{C}_{\mathrm{s}}+\mu_{\mathrm{p}} \mathrm{W}_{\mathrm{ww}}}$

The related critical value of braking effort $\left(F_{b w c}\right)$ above which sliding between the tread and the ground begins, is described by:

$F_{b w c}=\frac{\mu_{p} W_{w w}}{2}$

When sliding takes place in part of the contact patch (i.e., $i_{s}>i_{s c}$ ), the relationship between the braking effort developed by a wheel tire $\left(F_{b w}\right)$ and the skid can be described by

$F_{b w}=\mu_{p} W_{w w}\left[1-\frac{\mu_{s} W_{w w}\left(1-i_{s}\right)}{4 C_{s} i_{s}}\right]$ 
If the skid $\left(\mathrm{i}_{\mathrm{s}}\right) \leq\left(\mathrm{i}_{\mathrm{sc}}\right)$ or, the braking force $\left(\mathrm{F}_{\mathrm{bw}}\right) \leq\left(\mathrm{F}_{\mathrm{bwc}}\right)$ the relationship between the braking force and skid is linear, as shown in Fig. 11. The upper limit for the linear range of the braking force-skid relationship is given by Eq. 61 . A further increase of skid or braking force past the respective critical value results in the enlarge of the skidding state from leading edge towards the trailing edge of the contact patch. With this condition, the total braking force $\left(F_{b w}\right)$ developed in both adhesion and skidding regions is given by Eq. 62. The maximum braking force of a pneumatic tire on hard surfaces is usually reached somewhere between $10 \%$ and $15 \%$ of the skid [2]. Based on experimental data, it reaches a peak value between $15 \%$ and $20 \%$ skid [2].

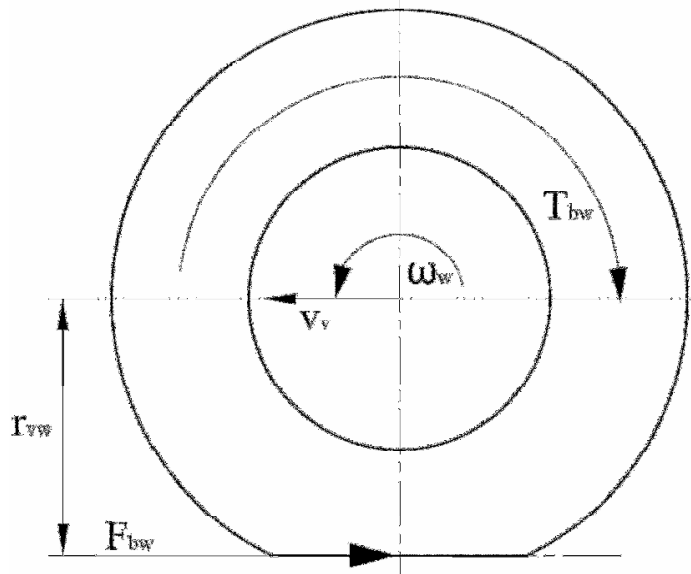

Fig. 12 The wheel tire under the action of the braking torque.

Any further increase of skid beyond these values leads to unsteady situation where the braking force $\left(F_{b w}\right)$ diminishes rapidly from the peak value $\left(\mu_{p} W_{v w}\right)$ to the pure sliding value $\left(\mu_{\mathrm{s}} \mathrm{W}_{\mathrm{vw}}\right)$. Finally, the braking force-skid relationship, given by Fig. 11, can be utilized for braking force $\left(\mathrm{F}_{\mathrm{bw}}\right)$ calculations.

It is obvious that, for a wheel tire, the braking torque applied ( $\left.T_{b w}\right)$ is acting in the opposite direction of the wheel angular speed $\left(\omega_{w}\right)$ and exists only when the linear speed of the tire center is not zero; $v_{v} \neq 0$, see Fig. 12. Moreover, when the skid becomes $100 \%$ (i.e., $\omega_{w}=0$ and $v_{v} \neq 0$ ), the braking torque ( $\left.T_{b w}\right)$ does not exceed the magnitude of the torque generated due to the braking effort $\left(F_{b w}\right)$ developed by the wheel tire at this moment (i.e., $T_{b w} \leq r_{v w} \mu_{\mathrm{s}} W_{v w}$ ). For the wheel tire under the action of braking torque ( $\left.T_{b w}\right)$, shown in Fig 12, the equation of motion can be described as follows

$\left(F_{b w} r_{w w}\right)-T_{b w}=I_{w} \dot{\omega}_{w}$

\section{Analysis of Dynamic Behavior for the Braking System with Anti-skid Unit}

The dynamic behavior of the pressure reducer and the anti-skid control unit is described by Eqs. 1 to 54, while the braked vehicle is described by Eqs. 55 to 63 . These equations were used to develop a computer simulation program using the SIMULINK package. This computer simulation was used to calculate transient response of the vehicle to step displacement of the braking lever of $33 \mathrm{~mm}$ magnitude. The vehicle initial speed $\left(v_{0}\right)$ is $150 \mathrm{~km} / \mathrm{h}$, the system pressure $\left(P_{S}\right)$ is $150 \mathrm{bar}$ and the return tank pressure $\left(\mathrm{P}_{\mathrm{T}}\right)$ is zero. The following assumptions are considered during calculations:

1. The vehicle is traveling on a level road (no grade resistance).

2. The aerodynamic resistance $\left(R_{a}\right)$ is negligible.

3. The share of vehicle normal load on the vehicle wheel tire is constant.

4. Braking torque $\left(T_{b}\right)$ is linearly proportional to braking pressure $\left(P_{B}\right)$. The average peak and sliding values of the coefficient of road adhesion $\left(\mu_{\mathrm{p}}\right)$ and $\left(\mu_{\mathrm{s}}\right)$ used for calculations are those of Truck Tires, bias-ply tire construction, tire type Goodyear Super Hi Miler (Rib) as follow [2] 
a. For dry concrete pavement; $\mu_{p}=0.850, \quad \mu_{s}=0.596$

b. For wet concrete pavement; $\mu_{p}=0.673, \quad \mu_{s}=0.458$

\section{Operating characteristics over dry concrete pavement}

Figure 13 shows the vehicle speed $\left(v_{v}\right)$, the wheel tire skid (i $\left.i_{s}\right)$ and the circumferential speed of wheel tire $\left(r_{v w} \omega_{w}\right)$ during hard braking simulation over dry concrete pavement (without anti-skid action). The wheels lock during braking and result in a skid value of $100 \%$ within 1 second of the initiation of braking. While the wheels come to a stop in 0.20 second, the vehicle itself does not come to a stop, only reduces in speed from $150 \mathrm{~km} / \mathrm{h}$ to $45 \mathrm{~km} / \mathrm{h}$ in 5 seconds, and completely stops within 7.1 seconds.

Figure 14 shows the vehicle speed $\left(v_{v}\right)$, the wheel tire skid $\left(i_{s}\right)$ and the circumferential speed of wheel tire $\left(r_{v w} \omega_{w}\right)$ during hard braking simulation over dry concrete pavement (with anti-skid action). The skid ratio is maintained between $2.4 \%$ and $27 \%$. The wheels do not lock allowing the vehicle to be steered. Further, the speed of the vehicle is reduced from $150 \mathrm{~km} / \mathrm{h}$ to $16 \mathrm{~km} / \mathrm{h}$ in 5 seconds and the vehicle completely stops in 5.6 seconds. Thus, a significantly reduction in vehicle speed is obtained by limiting the torque.

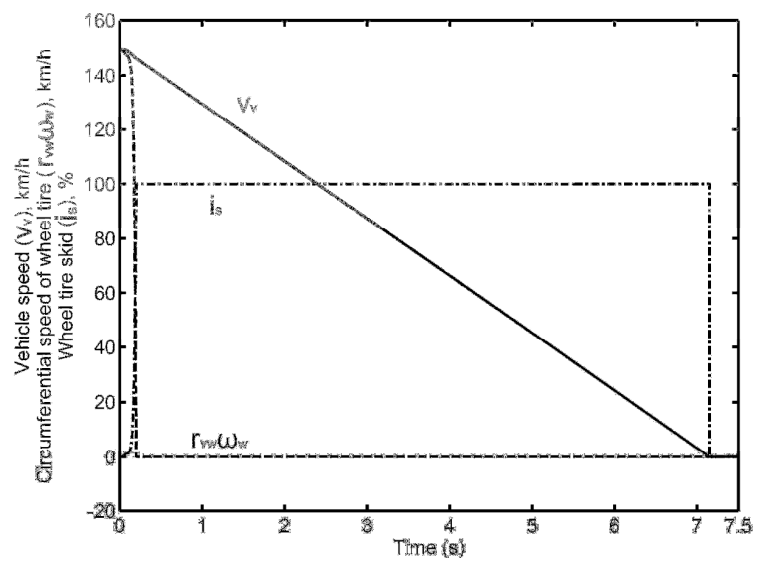

Fig. 13 The variation of vehicle speed, cirumferential speed and wheel tire skid duringbraking action over dry concrete pavement (Without anti-skid action).

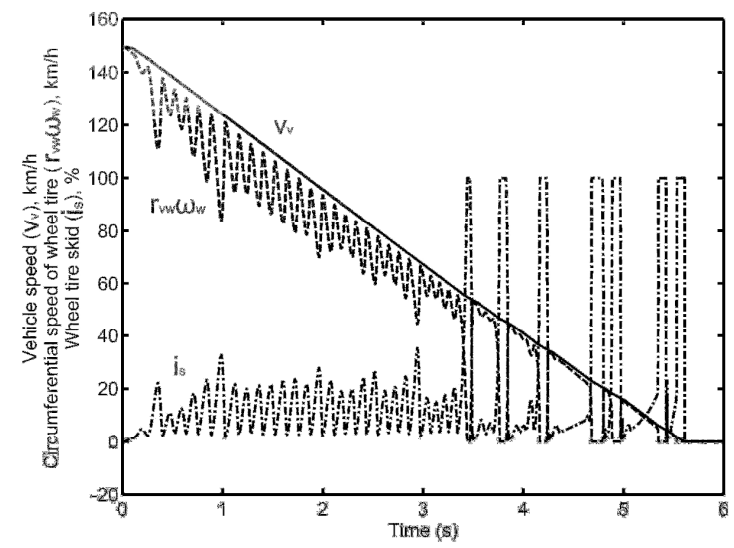

Fig. 14 The variation of vehicle speed, cirumferential speed and wheel tire skid during braking action over dry concrete pavement (With anti-skid action).

Figure 15 shows the operating characteristics simulation of the braking system with the mechanical anti-skid control unit over dry concrete pavement. The variation of braking pressure $\left(P_{B}\right)$, angular speed $\left(\omega_{B}\right)$ of push rod $(14)$ and angular speed $\left(\omega_{B C}\right)$ of flywheel (9) with time during the simulated braking action over dry concrete pavement are shown in Fig. 16.

It is noticed that, before braking action is applied, angular speed $\left(\omega_{\mathrm{Bc}}\right)$ of flywheel $(9)$ is increased until it matches angular speed $\left(\omega_{\mathrm{B}}\right)$ of push rod (14). While decelerating of push rod (14) as a result of the wheel tire deceleration at $t=0.0 \mathrm{~s}$, angular speed $\left(\omega_{B}\right)$ fluctuates and angular speed $\left(\omega_{B C}\right)$ of flywheel $(9)$ is decreased. The braking pressure $\left(P_{B}\right)$ decreasing when flywheel (9) drives push rod (14) (i.e. $\left.\omega_{B c}>\omega_{B}\right)$ and 


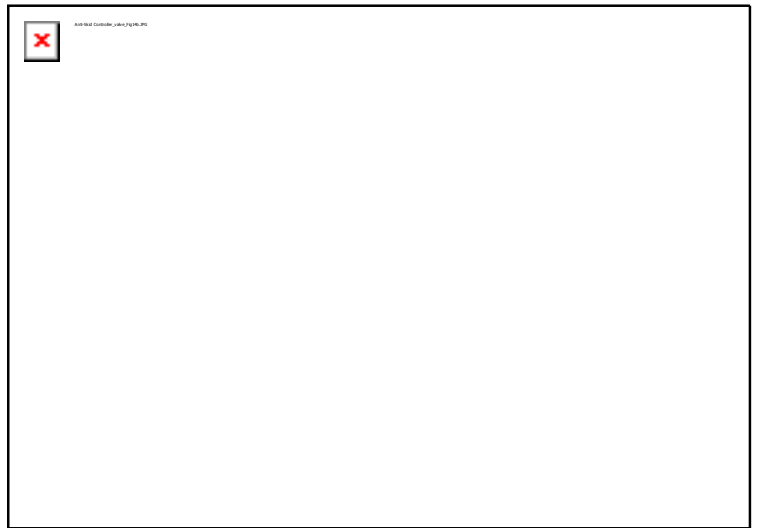

Fig. 15 The operating characteristics of the braking system with the hydro mechanical anti-skid control unit over dry concrete pavement.

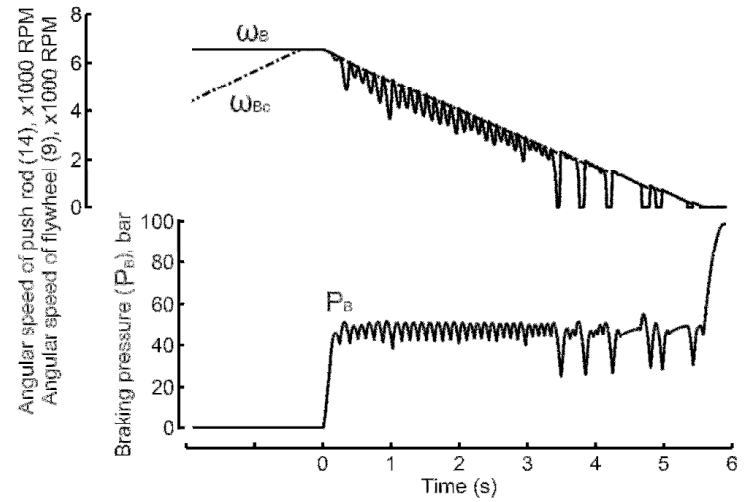

Fig. 16 The variation of braking pressure (PB) and the rotating parts angular speed of thehydro mechanical anti-skid control unit with time during the simulated braking action over dry concrete pavement.

this releasing the braking action. At $t=5.6 \mathrm{~s}$, when $\left(\omega_{\mathrm{B}}\right)$ and $\left(\omega_{\mathrm{BC}}\right)$ approach zero, braking pressure $\left(P_{B}\right)$ is increasing to the higher value of reduced pressure $\left(P_{R}\right)$ and finally reaches about 100 bars at $t=6 \mathrm{~s}$. Figure 15 shows the variation of braking pressure $\left(P_{B}\right)$, wheel tire skid $\left(i_{s}\right)$, vehicle speed $\left(v_{v}\right)$, circumferential speed of wheel tire $\left(r_{v w} \omega_{w}\right)$ and vehicle deceleration $\left(a_{v}\right)$ with time during the simulated braking action over dry concrete pavement. The braking action is applied at $t=0.0 \mathrm{~s}$.

As can be noticed, braking pressure $\left(P_{B}\right)$ fluctuates during the operation of the mechanical anti-skid control unit between the values of approximately 51 bar and 41 bar. The cycle of reducing and restoring the braking pressure is repeated several times, approximately from 7 to 10 , per second until the vehicle has slowed to a speed of about $50 \mathrm{~km} / \mathrm{h}$ and the vehicle deceleration is kept between $0.7 \mathrm{~g}$ and $0.8 \mathrm{~g}$. The wheel tire skid $\left(i_{s}\right)$ also remains between $2.4 \%$ and $27 \%$. Below vehicle speed of $50 \mathrm{~km} / \mathrm{h}$ and until the vehicle has completely stopped, when the wheel tire is locked, braking pressure $\left(P_{B}\right)$ is reduced to a lower value of about 25 bars and when vehicle speed is nearly zero, at $t=5.6 \mathrm{~s}$, braking pressure $\left(P_{B}\right)$ is increasing to the higher value of reduced pressure $\left(P_{R}\right)$.

The anti-lock action is achieved by this design over dry concrete pavement.

\section{Operating characteristics over wet concrete pavement}

Figure 17 shows the operating characteristics simulation of the braking system with the mechanical anti-skid control unit over wet concrete pavement. The variation of braking pressure $\left(P_{B}\right)$, angular speed $\left(\omega_{B}\right)$ of push rod $(14)$ and angular speed $\left(\omega_{B C}\right)$ of flywheel (9) with time during the simulated braking action over wet concrete pavement are shown in Fig. 18.

It can be shown that, for braking action over wet concrete pavement, the angular speed $\left(\omega_{B}\right)$ of push rod (14) fluctuates and also falls rapidly to zero which indicates 


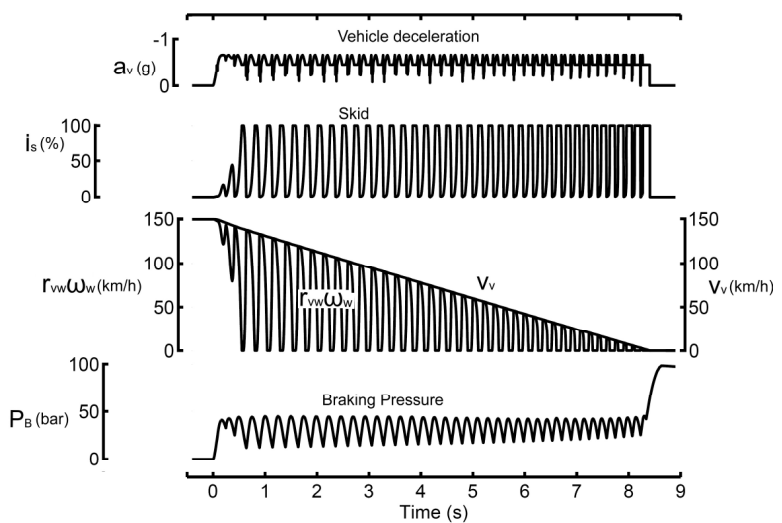

Fig. 17 The operating characteristics of the braking system with the hydro mechanical anti-skid control unit over wet concrete pavement.
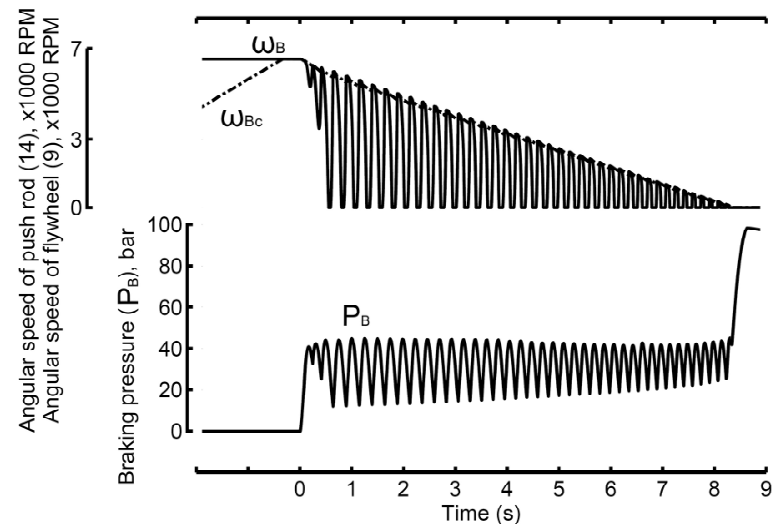

Fig. 18 Variation of braking pressure (PB) and the rotating parts angular speed of the hydro mechanical anti-skid control unit with time during braking action over wet concrete pavement.

occurrence of wheel tire skid earlier and more often than the case of dry pavement. The angular speed $\left(\omega_{\mathrm{BC}}\right)$ of flywheel $(9)$ is also decreasing to follow angular speed $\left(\omega_{B}\right)$ of push rod (14). The braking pressure $\left(P_{B}\right)$ decreasing when flywheel $(9)$ drives push rod (14) (i.e. $\omega_{B c}>\omega_{B}$ ) and this releasing the braking action. Figure 17 shows the variation of braking pressure $\left(P_{B}\right)$, wheel tire skid $\left(i_{s}\right)$, vehicle speed $\left(v_{v}\right)$, circumferential speed of wheel tire $\left(r_{v w} \omega_{w}\right)$ and vehicle deceleration $\left(a_{v}\right)$ with time during the simulated braking action over wet concrete pavement. The braking action is applied at $t=0.0 \mathrm{~s}$.

As can be noticed, the braking pressure $\left(\mathrm{P}_{\mathrm{B}}\right)$ fluctuates during the operation of the mechanical anti-skid control unit between the values of approximately 44 bars and 16 bars. The values of the braking pressure $\left(P_{B}\right)$ are relatively smaller than those of the dry pavement case. The cycle of reducing and restoring the braking pressure is repeated several times, approximately from 4 to 5 , per second until the vehicle has completely stopped and the vehicle deceleration is kept between $0.2 \mathrm{~g}$ and $0.66 \mathrm{~g}$. The vehicle deceleration is also smaller than that of dry pavement case. Therefore, it takes longer time for the vehicle for stopping completely at $t=8.4 \mathrm{~s}$ and the braking pressure $\left(P_{B}\right)$ is increasing to the higher value of the reduced pressure $\left(P_{R}\right)$ and reaches about 100 bars. The anti-lock action is achieved by this design over wet concrete pavement.

\section{CONCLUSION}

The dynamic behavior of an anti-skid braking system is investigated. The study included the deduction of the mathematical model describing the dynamic behavior of the studied system and the development of a simulation program using the MATLAB package. The investigation is carried out considering different road adhesion coefficients. The following are the main conclusions of the study.

- The braking action is improved with the operation of the anti-skid control unit as it limits the amount of braking torque applied to the wheels. 
- The vehicle speed reduction of $150 \mathrm{~km} / \mathrm{h}$ within 5 seconds is recovered from 45 to $16 \mathrm{~km} / \mathrm{h}$ (i.e. 64\%) and the total time required for the vehicle to completely stop is improved from 7.1 to 5.6 seconds (i.e. $21 \%$ ).

\section{REFERENCES}

[1] Heisler, Vehicle and Engine Technology, Warrendale Society of Automotive Engineers 1999.

[2] J. Y. Wong, Theory of Ground Vehicles, third edition. John Wiley \& Sons, Inc., Canada, 2001.

[3] A. H. Draz, M. Galal Rabie, A.I. Abdel-Aziz, M.S. Dwidar, "Dynamic Behavior of a Hydraulic Braking Valve Incorporating a Hydraulic Servo Actuator," Paper presented at the $13^{\text {th }}$ ASAT Conf., M.T.C., Cairo, 26 - 28 May 2009, Paper HC05

[4] M. Galal RABIE, Fluid Power Engineering, McGraw-Hill, NY, 2009.

[5] Mathworks Inc. support team. (1997). Matlab Reference Guide -. The Math Works Inc. 